\title{
Synthesis of Chemically Modified DNA
}

\author{
Arun Shivalingam ${ }^{1}$ and Tom Brown ${ }^{1 *}$ \\ ${ }^{1}$ Department of Chemistry, University of Oxford, Chemistry Research Laboratory, 12 Mansfield Road, \\ Oxford, OX1 3TA, UK \\ *Corresponding author: tom.brown@chem.ox.ac.uk
}

\begin{abstract}
Naturally occurring DNA is encoded by the four nucleobases adenine, cytosine, guanine and thymine. Yet minor chemical modifications to these bases, such as methylation, can significantly alter DNA function, and more drastic changes, such as replacement with unnatural base pairs, could expand its function. In order to realise the full potential of DNA in therapeutic and synthetic biology applications, our ability to 'write' long modified DNA in a controlled manner must be improved. This review highlights methods currently used for the synthesis of moderately long chemically modified nucleic acids (up to 1,000 base pairs), their limitations, and areas for future expansion.
\end{abstract}

\section{Introduction}

The ordered and addressable arrangement of the four nucleobases adenine (A), cytosine $(C)$, guanine $(G)$ and thymine $(T)$ in DNA allows our cells to store several gigabases of data in approximately seven picograms of material. The accessibility of this data is carefully controlled via chemical modification of the nucleobases, double helical DNA formation and compaction, as well as numerous DNA-protein interactions. Of these mechanisms, chemical modifications are of particular interest in that they increase the information storage capacity of DNA and enable its alteration. For example, controlled DNMT1-mediated methylation of cytosine modulates gene expression, ${ }^{[1]}$ whereas uncontrolled reactive oxygen species can oxidise nucleobases inducing mutations upon polymerase replication. Top-down studies have developed our understanding of these processes, however our ability to exploit this knowledge in synthetic biology applications and expand upon it using bottom-up approaches for therapeutic applications is constrained by our inability to 'read and write' modified DNA efficiently.

In the past decade, remarkable progress has been made in both of the above aspects for unmodified nucleic acids. Millions of DNA strands can now be sequenced in parallel using Illumina and Ion Torrent next generation sequencing platforms, ${ }^{[2]}$ whilst whole genomes such as that of Mycoplasma mycoides can be reconstructed from oligonucleotides. ${ }^{[3]}$ Yet of the two, our ability to write still lags behind our ability to read. Single base resolution of modified nucleobases, such as 5-methyl-, hydroxyl-, formyl- and carboxyl-C, is now possible, ${ }^{[4]}$ and with the rapid development of single molecule polymerase-independent nanopore sequencing this number may expand considerably still. ${ }^{[5]}$ On the other hand, the in vitro synthesis of highly ordered modified DNA, whether it contains (for example) amino acid side chains, epigenetic modifications, electrochemical markers or fluorophore tags, is still in its infancy partly due to the reliance of gene synthesis clean-up and amplification by 
PCR. Consequently, the focus of this review is to evaluate the current state of modified DNA synthesis (up to 1,000 base pairs) and highlight the challenges that have yet to be overcome.

\section{Chemical Synthesis}

Automated solid-phase phosphoramidite-based synthesis allows the routine and cheap production of oligonucleotides of $c a$. 100 bases. The principal chemical steps involved in each cycle were optimised by the early 1990s and have remained largely unchanged since (Figure 1). ${ }^{[6,7]}$ Step-wise coupling of phosphoramidites allows unparalleled control of DNA modification, however this comes at the cost of imperfect coupling ( 98.5-99.5\%) and uncontrolled mutagenesis due chemical exposure. ${ }^{[8]}$ Furthermore, the modifications to be introduced must be compatible with mildly acidic, strongly basic and oxidising conditions used in the various synthetic steps. This can be particularly challenging when multiple modifications, each with their own unique deprotection requirements, are used. When combined, this limits the length and yield of the oligonucleotide (if coupling efficiency = $99 \%, 100$-mer maximum yield $=36.6 \%$ ) as well as the number and type of modifications that can incorporated.

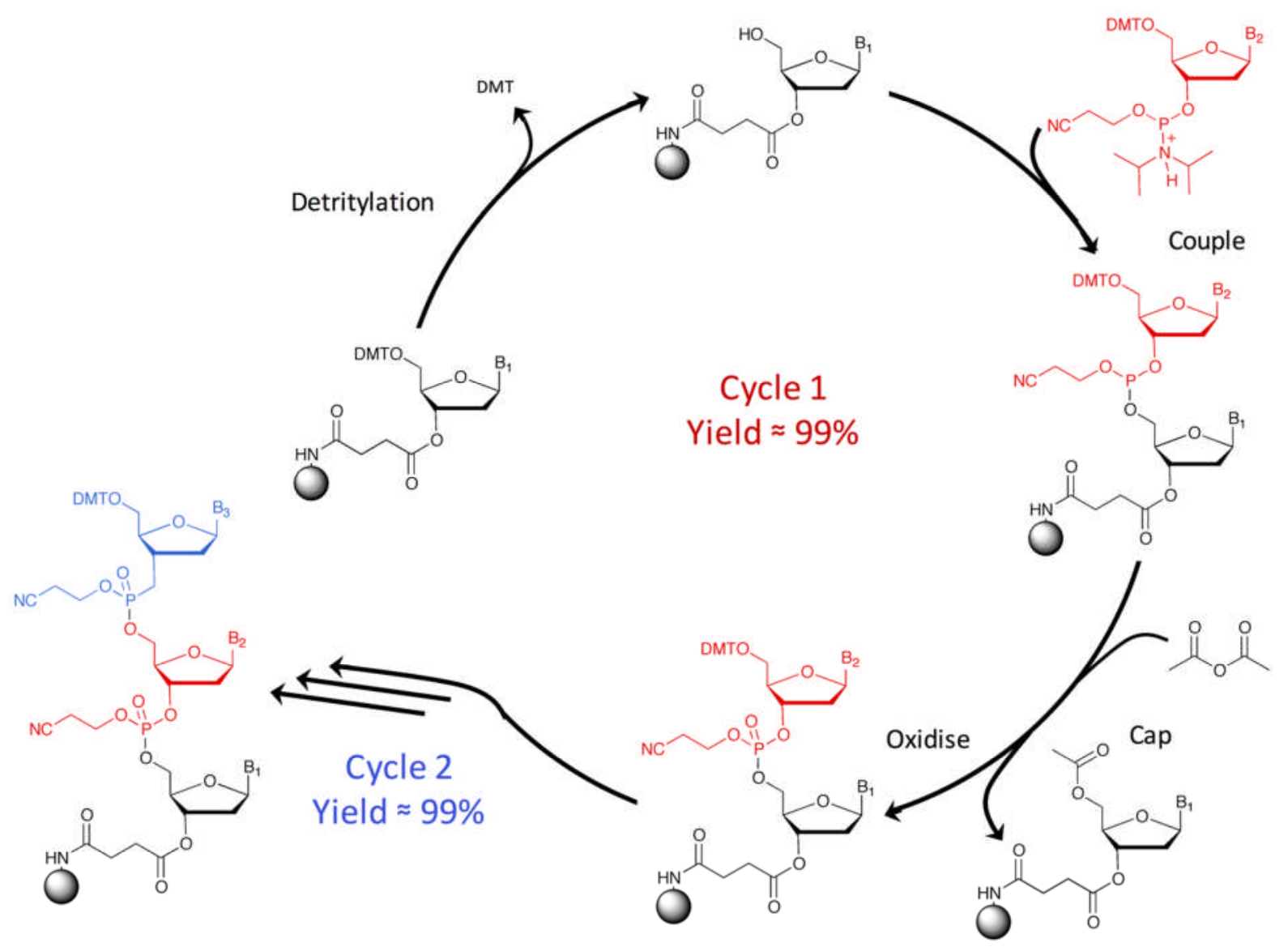

Figure 1. Standard automated solid-phase phosphoramidite-based oligonucleotide synthesis. The process consists of four steps (standard conditions in brackets) - 1) 5' hydroxyl detritylation ( $\mathrm{TCA} / \mathrm{CH}_{2} \mathrm{Cl}_{2}$ ), 2) phosphoramidite coupling (monomer, tetrazole), 3) uncoupled 5' hydroxyl capping $\left(\mathrm{Ac}_{2} \mathrm{O} /\right.$ pyridine/THF, $\mathrm{N}$-methylimidazole in $\left.\mathrm{MeCN}\right)$, and 4) phosphorus oxidation $\left(\mathrm{I}_{2}\right.$, $\mathrm{H}_{2} \mathrm{O} /$ Pyridine/THF). 
Efforts to optimise each of the four steps in the phosphoramidite oligonucleotide synthesis cycle has resulted in a diverse range of reagents (e.g. tetrazole, benzylthiotetrazole (BTT) or ethylthiotetrazole (ETT) coupling reagents; protecting groups that can be removed under 'ultramild' conditions; concentrated ammonium hydroxide, $0.1 \mathrm{M} \mathrm{NaOH}_{(\mathrm{aq})}$ or methanolic potassium carbonate solution deprotection) and optimised conditions (repetition of specific steps, temperature and/or time variations, changes to post-synthetic handling). ${ }^{[9]}$ Yet the gains in purity and yield due to changes in these specific parameters are challenging to quantify since they are likely to be interdependent and result in deletions, insertions or point mutations. Until recently these have been difficult to characterise in an accurate and cost-effective manner.

On the other hand, evaluation of incomplete detritylation and depurination, both of which impede the synthesis of full-length oligonucleotides and are linked to acidity, is more straightforward due to techniques for size separation of oligonucleotides and spectroscopic analysis. Alternative detritylation approaches include replacement of the Brønsted acid trichloroacetic acid (TCA) with chelating Lewis acids such as zinc bromide or mildly acidic sodium acetate buffer $(10 \mathrm{mM}, \mathrm{pH} 3.5) .{ }^{[10,11]}$ Unfortunately, the former requires use of the explosive nitromethane for rapid detritylation and the latter takes $\sim 30$ min for near quantitative conversion, reducing their commercial application. Depurination-inhibiting protecting groups such as amidines that decrease the $\mathrm{pK}_{\mathrm{a}}$ of the N7 (or N1) position of purines have also been explored but have not been widely adopted possibly due to slower deprotection rates. ${ }^{[12]}$ Finally, with the advent of high-throughput microarray oligonucleotide synthesisers with capacity for parallel synthesis of 12,000 to $1,000,000$ oligonucleotides, variations in platform design have given rise to the largest innovations in detritylation chemistry. Electrochemically generated acids allow deprotection in $\sim 5$ seconds, ${ }^{[13]}$ whereas photolabile 5 ' protecting groups avoid the use of acid altogether ${ }^{[14]}$ For inkject printed microarrays, it was found that active quenching of the acid by the oxidising solution significantly reduced depurination. ${ }^{[15]}$ However, these gains are tempered by loses in spatial resolution of reagents due to high throughput synthesis compared to conventional column synthesis, which ultimately constrains the maximum length of modified oligonucleotide synthesis to $150-200$ bases.

\section{Polymerase-Based Synthesis}

Therefore, the production of larger modified DNA must rely upon the assembly of smaller components. In this regard, the simplest method is to create the desired sequence by PCR amplification methods using a modified dNTP in place of the naturally occurring one. A key requirement for such dNTPs is that they can be incorporated and also read by polymerases. As a result, modifications that do not disturb the Watson-Crick base pairing face of the nucleobases are necessary; the C5 position of pyrimidines and the C7 position of 7deazapurines are usually chosen for functionalisation due to protrusion of the modification into the major groove of DNA, a structural feature that is more readily tolerated by polymerases (based on biochemical experiments and X-ray crystallographic data). ${ }^{[16,17]}$ Of these two positions the $\mathrm{C} 5$ pyrimidine modifications are more synthetically accessible and consequently more widely reported (Figure 2). ${ }^{[18,19]} \mathrm{C} 8$ purine modifications have been reported but their incorporation efficiency is noticeably worse. ${ }^{[20,21]}$ It should also be noted 
that the (de)stabilising properties of the modification must be carefully modulated for very large DNA duplex synthesis since most modifications, with the exception of C5 alkynyl pyrimidines and C7-alkynl 7-deazapurines, ${ }^{[22]}$ disrupt DNA duplex thermal stability by up to $1-2{ }^{\circ} \mathrm{C}$.

Correct optimisation of PCR extension time (typically lengthened) and temperature (typically lowered) is important for modified DNA synthesis but the choice of polymerase is most critical. Family B polymerases, such as KOD XL, Vent (exo-) and Pwo, are generally superior to family A polymerases. ${ }^{[18,23]}$ Indeed, for Cy3 and Cy5 fluorophore labelled dNTPs, genetically evolved family B Pfu variants are required for full incorporation of the modification. ${ }^{[2]}$ The properties of the resultant $1,000 \mathrm{bp}$ product neatly illustrates the fascinating behaviour of heavily modified DNA, in that conventional small molecule DNA intercalation was no longer possible and solubility was higher in organic rather than aqueous solvents. The latter point does, however, highlight that it would be favourable to control the density of modifications, which is sometimes achieved through the use of a mixture of modified and unmodified dNTPs. ${ }^{[25]}$ This is most evident when bulky modifications must be incorporated sequentially along a template; this results in some templates being more 'modifiable' than other.

Perhaps the main limitation of this method is that it is an 'all or nothing' approach. If all $A, C$, $\mathrm{G}$ or $\mathrm{T}$ sites of the product are replaced by a modified nucleotide $(\mathrm{X})$, then the product is a defined single species; if there is a mixture of modifications introduced via a mixture of a natural dNTP and the unnatural dXTP for either of the A, C, G or T sites, then a range of products is obtained with varying modification content. For some applications, such as synthesis of fluorescent in-situ hybridisation probes, the mixed products could be of benefit as this enables custom mixtures of multiple fluorophores that give rise to unique optical output. ${ }^{[25,26]}$ Indeed, for aptamers (nucleic acid antibody equivalents) this would be ideal as fully modified sequences may not have sufficient structural diversity for target binding. ${ }^{[27]}$ Yet the problem lies in decoding the signal to retrieve the specific modified sequence used.

A

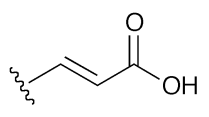

B

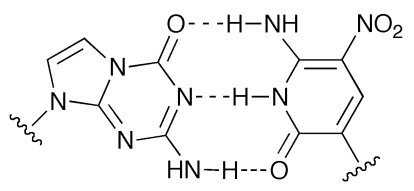

$\mathrm{dP}$
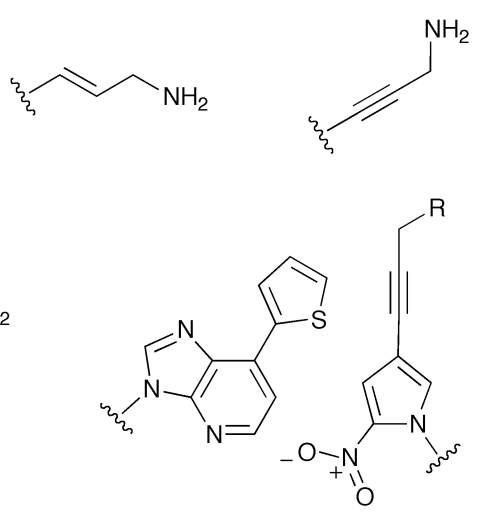

dDs
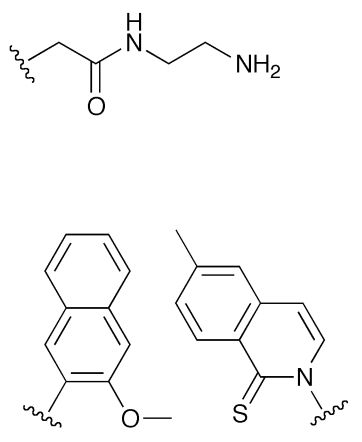

dNaM d5SICS

Figure 2. Modifications that have been incorporated into triphosphates. A) shows a sample of simpler C5 pyrimidine modifications. B) illustrates the structure of the three most successful unnatural base pairs reported to date. Deoxyribose sugars are omitted for clarity. For $\mathrm{dPx}, \mathrm{R}=\mathrm{H}$ or $\mathrm{CH}(\mathrm{OH}) \mathrm{CH}_{2}(\mathrm{OH})$. 
Finally, if single PCR products are required, given that polymerases have evolved to recognise only the naturally occurring bases / base pairs (AT, TA, CG, GC), only four modifications can be made per PCR generated product. ${ }^{[23]}$ This premise has been challenged in recent years through the use of unnatural base pairs. To date three unnatural base pairs have been reported with very high stability and replication fidelity $(>99.8 \%)$ under defined conditions (Figure 2). ${ }^{[28-30]}$ Selectivity is maintained either by alternative hydrogen bonding patterns or predominately hydrophobic interactions. The 'expanded genetic alphabet' is particularly intriguing due its promise of enhanced data storage but has so far been principally used for aptamer selection where its presence is vital for function ( $>100$-fold increase in affinity if substituted for the natural base analogue). ${ }^{[31,32]}$ Whilst the dNaMd5SICS base pair has been shown to be biocompatible in E. Coli, caution must be taken as the dNTPs required for its replication cannot be expressed natively in cells. ${ }^{[33]}$

\section{Ligation-Based Synthesis}

The above PCR-based methods cannot be used to produce chemically modified DNA containing specific modifications at predefined loci. For such site-specific incorporation of modifications in long DNA, the ideal reaction would involve direct stepwise ligation of shorter chemically synthesised modified oligonucleotides. This would bypass the inability of polymerases to detect modifications that are not on present the Watson-Crick hydrogen bonding face, and would allow for a much wider range of modifications, including those to sugar and phosphate. To this end, DNA ligases can be used, however the templated assembly of $>1000 \mathrm{bp}$ genes using this method has been restricted to unmodified oligonucleotides. ${ }^{[34-36]}$ This is surprising given the growing interest in the epigenome and in particular the role that oxidised forms of 5-methyl-C play in it. ${ }^{[37]} \mathrm{A}$ reason for this could be ligation inefficiency; post-ligation enrichment of the desired gene by PCR or cloning is often used, ${ }^{[34]}$ which would erase all modifications introduced. Yet, with optimisation, ligation methods could feasibly be used to synthesize large DNA constructs with highly ordered and predetermined arrangements of modifications. Precedent for this comes from templated assembly of $5^{\prime}$ phosphorylated trimers and pentamers bearing peptide moieties using T4 DNA ligase. ${ }^{[38,39]}$ Products of 50-150 bases were synthesised (10-50 independent ligations) with efficiencies reaching ca. 98\%. Promisingly, these products could be read by Vent (exo-) polymerase and re-synthesised by T4 DNA ligase, enabling their use in inhibitor identification by in vitro selection.

In this context, chemical ligation is appealing in that small molecule chemical reactions can be highly efficient, and should be more agnostic than ligase enzymes in terms of the substrates to be ligated. ${ }^{[40]}$ The first example of this was a condensation reaction using cyanogen bromide, ${ }^{[41]}$ whilst later methods involved the spontaneous displacement of a tosylate / iodo group from the $5^{\prime}$ position of oligonucleotides using $3^{\prime}$ thiophosphorylated oligonucleotides. ${ }^{[42,43]}$ Whilst promising, these methods failed to gain wider adoption due to the lack of controlled ligation, stability of components in water and toxicity. To this end, development of bifunctional 5'-azide 3'-alkyne modified oligonucleotides for use in coppercatalysed cycloaddition 'click' chemistry was developed in our group (Figure 3). ${ }^{[4]}$ The resultant triazole linkage, whilst not a natural phosphodiester, is remarkably biocompatible and non-toxic. Successive refinement of the structure based on the hypothesis that the triazole acts as a hydrogen bond acceptor, which was later supported by NMR studies, ${ }^{[45]}$ in 
combination with efforts to reduce the synthetic burden of monomer synthesis resulted in a second generation version that is faithfully replicated. ${ }^{[46]}$ This is the first fully modified nucleic acid backbone that is compatible with DNA and RNA polymerases in vitro and in mammalian cells. ${ }^{[47]}$ As proof of principle, a 300 base oligonucleotide containing two triazole linkages was prepared. Further work is ongoing to adapt this methodology for larger modified DNA synthesis.
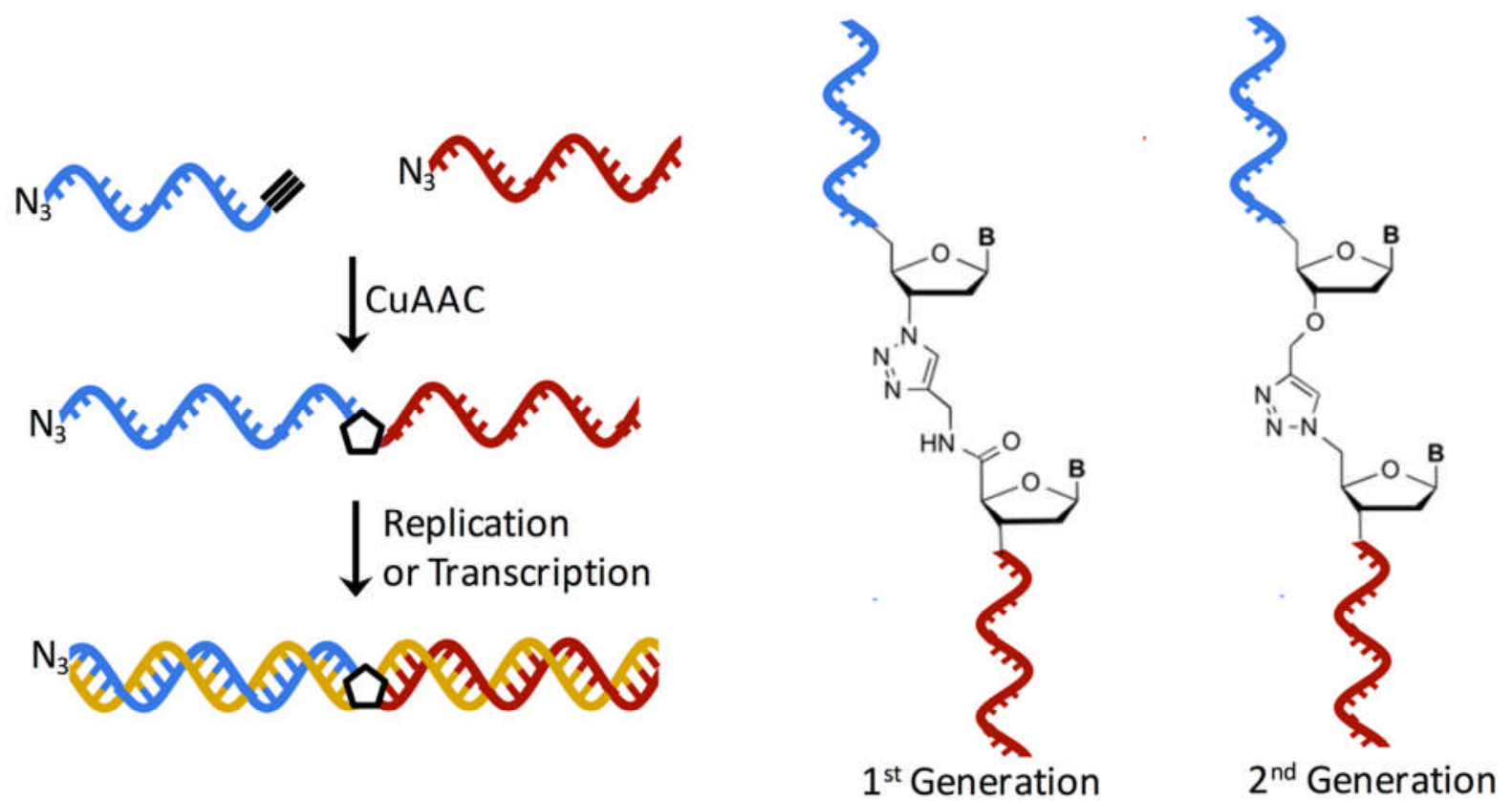

Figure 3. Chemical ligation using copper-catalysed azide-alkyne cycloaddition (CuAAC) 'click' chemistry to generate $1^{\text {st }}$ and $2^{\text {nd }}$ generation biocompatible triazole internucleoside linkages.

\section{Post-synthetic Modification}

In principle all of the above methodologies can be used in conjunction with post-synthetic modification of DNA. In effect, this reduces the chemical or enzymatic synthetic burden by reducing monomer complexity. Simple small functional handles, such as aldehydes, linear alkynes, cycloalkynes, azides, carboxylic acids or primary amines, can be introduced as nucleobase modifications during enzymatic or chemical synthesis, and subsequently reacted to generate the final desired modification. A second pre-labelling step is sometimes required to access handles such as azides due to the chemical instability during solid-phase oligonucleotide synthesis. Of the numerous coupling methods that have been established, there are to date just a few orthogonal reactions ${ }^{[48,49]}$ (e.g. amide formation, inverse DielsAlder reaction, ${ }^{[50]}$ copper-catalysed ${ }^{[51]} /$ strain-promoted $^{[52]}$ Huisgen [2+3] cycloaddition and oxime formation ${ }^{[53]}$ ). As a consequence, selective protection of different moieties is required for the introduction of multiple modifications, with one of the best examples being the two different levels of terminal alkyne protection used for three independent copper 'click' reactions by solid phase synthesis. ${ }^{[54]}$ Despite its synthetic ease, the main drawbacks to post-synthetic functionalization are incomplete or slow reactions depending upon reactant concentrations, partly limited by solubility issues. Hence the methodology is most efficiently used with solid phase immobilised oligonucleotides, where the reactants can be used in excess in a suitable solvent and easily removed. 


\section{Conclusions}

The synthesis of highly modified DNA is constrained by the limited ability of polymerases to recognise modifications to the nucleobase, phosphate or sugar. Consequently, the chemical complexity of polymerase generated DNA will always be limited by the number of different dNTPs that are available, and the number of different bases / base pairs that can be read and written by the polymerase enzyme. If locus/sequence specific modifications to DNA are required, the problem becomes intractable. On the other hand, for the generation of random libraries, the use of modified dNTPs has clear advantages but is currently handicapped by our limited ability to decode the modifications and the low / inconsistent yields of triphosphate (dNTP) synthesis; ${ }^{[55]}$ novel high yielding methodologies are required. For ordered and patterned synthesis of modified DNA, it is evident that a combination of chemical and enzymatic synthetic methods could be used. The high number of coupling steps achievable by solid phase synthesis (up to 150 with appreciable final yields) highlights that chemical coupling can be exceptionally efficient, but that it does have a finite limit. This is partly due to the architecture of the solid supports used conventionally. Therefore, to achieve long modified DNA synthesis, a compromise must be made between oligonucleotide length, purity, and the number of ligation reactions. The issue of oligonucleotide purity is particularly important given that post-assembly error correction methods currently used in PCR-based gene synthesis ${ }^{[56]}$ will have detrimental effects when synthesising modified DNA; they can remove modifications and replace them with unmodified sections of DNA. Therefore, it is essential that solid-phase automated oligonucleotide synthesis, in addition to ligation methods, be optimised in future if the synthesis of very long chemically modified DNA constructs is to become a routine exercise.

\section{References}

[1] Song J, Rechkoblit O, Bestor TH, Patel DJ. (2011) Structure of DNMT1-DNA Complex Reveals a Role for Autoinhibition in Maintenance DNA Methylation. Science (80-. ). 331, 1036-1040.

[2] Metzker ML. (2010) Sequencing technologies [mdash] the next generation. Nat Rev Genet. 11, 31-46.

[3] Gibson DG, Glass JI, Lartigue C, Noskov VN, Chuang R-Y, Algire MA, et al. (2010) Creation of a Bacterial Cell Controlled by a Chemically Synthesized Genome. Science (80-. ). 329, 52-56.

[4] Booth MJ, Raiber E-A, Balasubramanian S. (2015) Chemical Methods for Decoding Cytosine Modifications in DNA. Chem. Rev. 115, 2240-2254.

[5] Schreiber J, Wescoe ZL, Abu-Shumays R, Vivian JT, Baatar B, Karplus K, et al. (2013) Error rates for nanopore discrimination among cytosine, methylcytosine, and 
hydroxymethylcytosine along individual DNA strands. Proc. Natl. Acad. Sci. 110, 18910-18915.

[6] Caruthers MH, Barone AD, Beaucage SL, Dodds DR, Fisher EF, McBride L, et al. (1987) [15] Chemical synthesis of deoxyoligonucleotides by the phosphoramidite method. In: Enzymology BT-M in, editor. Recombinant DNA Part E. Academic Press; 1987. p. 287313.

[7] Caruthers MH. (1991) Chemical synthesis of DNA and DNA analogs. Acc. Chem. Res. 24, 278-284.

[8] Rayner S, Brignac S, Bumeister R, Belosludtsev Y, Ward T, Grant O, et al. (1998) MerMade: An Oligodeoxyribonucleotide Synthesizer for High Throughput Oligonucleotide Production in Dual 96-Well Plates. Genome Res. 8, 741-747.

[9] Ellington A, Pollard JD. (2001) Introduction to the Synthesis and Purification of Oligonucleotides. In: Current Protocols in Nucleic Acid Chemistry. John Wiley \& Sons, Inc.; 2001.

[10] Krotz AH, Cole DL, Ravikumar VT. (2003) Synthesis of Antisense Oligonucleotides with Minimum Depurination. Nucleosides, Nucleotides and Nucleic Acids. 22, 129-134.

[11] Matteucci MD, Caruthers MH. (1980) The use of zinc bromide for removal of dimethoxytrityl ethers from deoxynucleosides. Tetrahedron Lett. 21, 3243-3246.

[12] Froehler BC, Matteucci MD. (1983) Dialkylformamldines: depurination resistant N6protecting group for deoxyadenosine. Nucleic Acids Res. 11, 8031-8036.

[13] Egeland RD, Southern EM. (2005) Electrochemically directed synthesis of oligonucleotides for DNA microarray fabrication. Nucleic Acids Res. 33, e125-e125.

[14] Pease AC, Solas D, Sullivan EJ, Cronin MT, Holmes CP, Fodor SP. (1994) Lightgenerated oligonucleotide arrays for rapid DNA sequence analysis. Proc. Natl. Acad. Sci. U. S. A. 91, 5022-5026.

[15] LeProust EM, Peck BJ, Spirin K, McCuen HB, Moore B, Namsaraev E, et al. (2010) Synthesis of high-quality libraries of long (150mer) oligonucleotides by a novel depurination controlled process. Nucleic Acids Res. 38, 2522-2540.

[16] Obeid S, Baccaro A, Welte W, Diederichs K, Marx A. (2010) Structural basis for the 
synthesis of nucleobase modified DNA by Thermus aquaticus DNA polymerase. Proc. Natl. Acad. Sci. 107, 21327-21331.

[17] Bergen K, Steck A-L, Strütt S, Baccaro A, Welte W, Diederichs K, et al. (2012) Structures of KlenTaq DNA Polymerase Caught While Incorporating C5-Modified Pyrimidine and C7-Modified 7-Deazapurine Nucleoside Triphosphates. J. Am. Chem. Soc. 134, 11840-11843.

[18] Kuwahara M, Nagashima J, Hasegawa M, Tamura T, Kitagata R, Hanawa K, et al. (2006) Systematic characterization of 2'-deoxynucleoside- 5'-triphosphate analogs as substrates for DNA polymerases by polymerase chain reaction and kinetic studies on enzymatic production of modified DNA. Nucleic Acids Res. 34, 5383-5394.

[19] Ren X, El-Sagheer AH, Brown T. (2015) Azide and trans-cyclooctene dUTPs: incorporation into DNA probes and fluorescent click-labelling. Analyst [Internet]. 140, 2671-2678. Available from: http://dx.doi.org/10.1039/C5AN00158G

[20] Thomas JM, Yoon J-K, Perrin DM. (2009) Investigation of the Catalytic Mechanism of a Synthetic DNAzyme with Protein-like Functionality: An RNaseA Mimic? J. Am. Chem. Soc. 131, 5648-5658.

[21] Čapek P, Cahová H, Pohl R, Hocek M, Gloeckner C, Marx A. (2007) An Efficient Method for the Construction of Functionalized DNA Bearing Amino Acid Groups through Cross-Coupling Reactions of Nucleoside Triphosphates Followed by Primer Extension or PCR. Chem. - A Eur. J. 13, 6196-6203.

[22] Seela F, Budow S, Shaikh KI, Jawalekar AM. (2005) Stabilization of tandem dG-dA base pairs in DNA-hairpins: replacement of the canonical bases by 7-deaza-7propynylpurines. Org. Biomol. Chem. 3, 4221-4226.

[23] Jäger S, Rasched G, Kornreich-Leshem H, Engeser M, Thum O, Famulok M. (2005) A Versatile Toolbox for Variable DNA Functionalization at High Density. J. Am. Chem. Soc. 127, 15071-15082.

[24] Ramsay N, Jemth A-S, Brown A, Crampton N, Dear P, Holliger P. (2010) CyDNA: Synthesis and Replication of Highly Cy-Dye Substituted DNA by an Evolved Polymerase. J. Am. Chem. Soc. 132, 5096-5104.

[25] Tasara T, Angerer B, Damond M, Winter H, Dörhöfer S, Hübscher U, et al. (2003) Incorporation of reporter molecule-labeled nucleotides by DNA polymerases. II. Highdensity labeling of natural DNA. Nucleic Acids Res. 31, 2636-2646. 
[26] Ren X, El-Sagheer AH, Brown T. (2016) Efficient enzymatic synthesis and dual-colour fluorescent labelling of DNA probes using long chain azido-dUTP and BCN dyes. Nucleic Acids Res. [Internet]. Available from:

http://nar.oxfordjournals.org/content/early/2016/01/26/nar.gkw028.abstract

[27] Kraemer S, Vaught JD, Bock C, Gold L, Katilius E, Keeney TR, et al. (2011) From SOMAmer-Based Biomarker Discovery to Diagnostic and Clinical Applications: A SOMAmer-Based, Streamlined Multiplex Proteomic Assay. PLoS One. 6, e26332.

[28] Kimoto M, Kawai R, Mitsui T, Yokoyama S, Hirao I. (2009) An unnatural base pair system for efficient PCR amplification and functionalization of DNA molecules. Nucleic Acids Res. 37, e14-e14.

[29] Malyshev DA, Dhami K, Quach HT, Lavergne T, Ordoukhanian P, Torkamani A, et al. (2012) Efficient and sequence-independent replication of DNA containing a third base pair establishes a functional six-letter genetic alphabet. Proc. Natl. Acad. Sci. 109, 12005-12010.

[30] Yang Z, Chen F, Alvarado JB, Benner SA. (2011) Amplification, Mutation, and Sequencing of a Six-Letter Synthetic Genetic System. J. Am. Chem. Soc. 133, 1510515112.

[31] Sefah K, Yang Z, Bradley KM, Hoshika S, Jiménez E, Zhang L, et al. (2014) In vitro selection with artificial expanded genetic information systems. Proc. Natl. Acad. Sci. 111, 1449-1454.

[32] Kimoto M, Yamashige R, Matsunaga K, Yokoyama S, Hirao I. (2013) Generation of high-affinity DNA aptamers using an expanded genetic alphabet. Nat Biotech. 31, 453-457.

[33] Malyshev DA, Dhami K, Lavergne T, Chen T, Dai N, Foster JM, et al. (2014) A semisynthetic organism with an expanded genetic alphabet. Nature. 509, 385-388.

[34] Au L-C, Yang F-Y, Yang W-J, Lo S-H, Kao C-F. (1998) Gene Synthesis by a LCR-Based Approach: High-Level Production of Leptin-L54 Using Synthetic Gene inEscherichia coli. Biochem. Biophys. Res. Commun. 248, 200-203.

[35] Schatz Octavian (Altomunster D. (2006) Method for the synthesis of DNA fragments. 
[36] Urdea Mickey S. (San Francisco CWBD (Eau CW. (1985) Multiple reactor system and method for polynucleotide synthesis.

[37] Wu H, Zhang Y. (2015) Charting oxidized methylcytosines at base resolution. Nat. Struct. Mol. Biol. 22, 656-661.

[38] Guo C, Watkins CP, Hili R. (2015) Sequence-Defined Scaffolding of Peptides on Nucleic Acid Polymers. J. Am. Chem. Soc. 137, 11191-11196.

[39] Hili R, Niu J, Liu DR. (2013) DNA Ligase-Mediated Translation of DNA Into Densely Functionalized Nucleic Acid Polymers. J. Am. Chem. Soc. 135, 98-101.

[40] Qiu J, El-Sagheer AH, Brown T. (2013) Solid phase click ligation for the synthesis of very long oligonucleotides. Chem. Commun. [Internet]. 49, 6959-6961. Available from: http://dx.doi.org/10.1039/C3CC42451K

[41] Shabarova ZA, Merenkova IN, Oretskaya TS, Sokolova NI, Skripkin EA, Alexeyeva E V, et al. (1991) Chemical ligation of DNA: the first non-enzymatic assembly of a biologically active gene. Nucleic Acids Res. 19, 4247-4251.

[42] Xu Y, Kool ET. (1998) Chemical and enzymatic properties of bridging 5'-Sphosphorothioester linkages in DNA. Nucleic Acids Res. 26, 3159-3164.

[43] Herrlein MK, Nelson JS, Letsinger RL. (1995) A Covalent Lock for Self-Assembled Oligonucleotide Conjugates. J. Am. Chem. Soc. 117, 10151-10152.

[44] El-Sagheer AH, Brown T. (2009) Synthesis and Polymerase Chain Reaction Amplification of DNA Strands Containing an Unnatural Triazole Linkage. J. Am. Chem. Soc. 131, 3958-3964.

[45] Dallmann A, El-Sagheer AH, Dehmel L, Mügge C, Griesinger C, Ernsting NP, et al. (2011) Structure and Dynamics of Triazole-Linked DNA: Biocompatibility Explained. Chem. - A Eur. J. 17, 14714-14717.

[46] El-Sagheer AH, Sanzone AP, Gao R, Tavassoli A, Brown T. (2011) Biocompatible artificial DNA linker that is read through by DNA polymerases and is functional in Escherichia coli. Proc. Natl. Acad. Sci. 108, 11338-11343.

[47] Birts CN, Sanzone AP, El-Sagheer AH, Blaydes JP, Brown T, Tavassoli A. (2014) Transcription of Click-Linked DNA in Human Cells. Angew. Chemie Int. Ed. 53, 2362- 
2365.

[48] Gutsmiedl K, Fazio D, Carell T. (2010) High-Density DNA Functionalization by a Combination of Cu-Catalyzed and Cu-Free Click Chemistry. Chem. - A Eur. J. 16, 68776883.

[49] Schoch J, Staudt M, Samanta A, Wiessler M, Jäschke A. (2012) Site-Specific One-Pot Dual Labeling of DNA by Orthogonal Cycloaddition Chemistry. Bioconjug. Chem. 23, 1382-1386.

[50] Schoch J, Wiessler M, Jäschke A. (2010) Post-Synthetic Modification of DNA by Inverse-Electron-Demand Diels-Alder Reaction. J. Am. Chem. Soc. 132, 8846-8847.

[51] Gierlich J, Burley GA, Gramlich PME, Hammond DM, Carell T. (2006) Click Chemistry as a Reliable Method for the High-Density Postsynthetic Functionalization of AlkyneModified DNA. Org. Lett. 8, 3639-3642.

[52] Marks IS, Kang JS, Jones BT, Landmark KJ, Cleland AJ, Taton TA. (2011) StrainPromoted "Click" Chemistry for Terminal Labeling of DNA. Bioconjug. Chem. 22, 1259-1263.

[53] Crisalli P, Hernández AR, Kool ET. (2012) Fluorescence Quenchers for Hydrazone and Oxime Orthogonal Bioconjugation. Bioconjug. Chem. 23, 1969-1980.

[54] Gramlich PME, Warncke S, Gierlich J, Carell T. (2008) Click-Click-Click: Single to Triple Modification of DNA. Angew. Chemie Int. Ed. 47, 3442-3444.

[55] Burgess K, Cook D. (2000) Syntheses of Nucleoside Triphosphates. Chem. Rev. 100, 2047-2060.

[56] Ma S, Saaem I, Tian J. (2016) Error correction in gene synthesis technology. Trends Biotechnol. 30, 147-154. 